UDK 784.3 Procházka J.

Jernej Weiss

Filozofska fakulteta Univerze v Ljubljani

Philosophical Faculty, University of Ljubljana

\title{
Josip Procházka (1874-1956) kot »češko-slovenski« skladatelj samospevov
}

\section{Josip Procházka (1874-1956) as 'Czech-Slovenian' Song Composer}

Ključne besede: Josip Procházka, Novi akor$d i$, primerjalna analiza, slovenski samospev

\section{IZVLEČEK}

Avtor pričujočega prispevka skuša s primerjalno analizo določiti bistvene kompozicijskotehnične značilnosti in estetske usmeritve $\mathrm{v}$ enajstih samospevih Josipa Procházke, objavljenih v reviji Novi akordi, ki jih je skladatelj napisal za časa njegovega glasbeno-pedagoškega delovanja na Slovenskem. V želji po določitvi vloge in pomena omenjenih samospevov $\mathrm{v}$ širšem ustvarjalnem kontekstu samospeva na Slovenskem pa se avtor pričujočega prispevka kritično opredeli do razumevanja napredka $\mathrm{v}$ funkciji utrjevanja nacionalne samobitnosti, ki je zdi se pomembno zarisalo meje uredniški politiki v navidez "zunajstrankarski« reviji Novi akordi.
Keywords: Josip Procházka, 'Novi akordi', comparative analysis, Slovenian Song

\section{ABSTRACT}

Through a comparative analysis the author of this paper attempts to determine the essential compositional-technical characteristics, as well as esthetical directions in Josip Procházka's eleven songs published in the magazine 'Novi akordi', written by the composer during his musical-pedagogical work in Slovenia. Wishing to determine the role and significance of the aforementioned songs in a broader creative context of the song in Slovenia, the author takes a critical view of understanding the progress as the strengthening of 'national originality', which seems to have set significant boundaries to the editorial policy in the seemingly 'non-party' magazine 'Novi akordi'.

Pričujoči razmislek temelji na dveh izhodiščih. Prvo opazuje posledice nacionalnih delitev, ki so še vse v 20. stoletje bolj ali manj usodno zaznamovale dogajanje v glasbeni kulturi na Slovenskem in s predrugačenjem v osnovi prevzetih idejnih okvirov tudi v navidez "zunajstrankarski«1 reviji Novi akordi pomembno zarisale okvire takrat-

1 Avtor udarnega besedila v posebni prilogi Ljubljanskega zvona, za katerim je uradno stalo "založništvo«, je bil prav gotovo Gojmir Krek. Resnična želja uredništva, ki jo je izrazil naj bi bila zunajstrankarstvo, saj »naj 
ni uredniški politiki. Drugo pa skuša z razgrnitvijo bistvenih kompozicijsko-tehničnih in estetskih izhodišč v enajstih samospevih Josipa Procházke, izdanih v Novih akordih za časa skladateljevega delovanja na Slovenskem, določiti vlogo in pomen omenjenih samospevov v širšem ustvarjalnem kontekstu samospeva na Slovenskem.

Zdi se, da je idejo nacionalnega v glasbi v začetku 20. stoletja na Slovenskem čez noč zamenjala, v zahodno-evropskem merilu veliko bolj aktualna ideja glasbenega napredka, ${ }^{2}$ ki je hotela kot izključno slovensko blago enakovredno prodreti na evropsko glasbeno tržišče. V imenu slednje se je vnaprej izključevalo vse vsaj malce sumljive politične emigrante, saj je bila ideja napredka za presojo umetniških dosežkov enkrat bolj, drugič spet malo manj pomemben estetski kriterij. Anton Lajovic si je s somišljeniki takoj po koncu prve svetovne vojne močno prizadeval za popolno suverenost slovenske glasbe, ki naj bi bila le tako lahko obvarovana "strupa nemške glasbe«. ${ }^{3}$ Idejni okopi so se seveda kazali že mnogo prej. Iz glasbe na Slovenskem se je zdelo potrebno kar najhitreje ustvariti slovensko glasbo ter deloma prikrojiti glasbeno zgodovinski spomin. Nujno je bilo prekiniti z vsem minulim in se opreti zgolj na slovenske dosežke. V osnovi precej avantgardno mišljenje, se je tudi pri največjih zagovornikih »novega« kaj kmalu izrodilo v romantično razpetost med idealom in stvarnostjo. Sočasne kompozicijskotehnične modele je bilo nujno kar se da hitro uvoziti od drugih, v idejnem pogledu sorodnih narodov. Za slovensko glasbeno kulturo so bili tako toliko bolj pomembni stiki s številno češko glasbeno imigracijo na Slovenskem, ki je s seboj prinašala ustvarjalne dosežke glasbene kulture v čeških deželah na prehodu iz 19. v 20. stoletje.

Josef, ${ }^{4}$ slovensko Josip Procházka je imel kot Dvořákov učenec kompozicije vsekakor dobre predispozicije za kar se da uspešno glasbeno delovanje na Slovenskem. ${ }^{5} \mathrm{~K}$ ugodni poziciji je zdi se pripomoglo tudi njegovo pedagoško delovanje na šoli Glas-

bi se pod praporom Novih akordov našli vsi skladatelji katere koli umetniške struje.« KREK, GOJMIR, Novi akordi, Ur. AŠKERC, ANTON, Ljubljanski zvon 21 (1901), Narodna tiskarna, Ljubljana 1901, 576.

2 Ferruccio Busoni je že leta 1907 v svojem Konceptu nove estetike v glasbeni umetnosti (Entwurf einer neuen Ästhetik der Tonkunst) zapisal: »Naloga ustvarjalca je predvsem postavljanje zakonov in ne sledenje le tem. Kdor zgolj sledi danim zakonom preneha biti ustvarjalec."BUSONI, FERRUCCIO, Entwurf einer neuen Ästhetik der Tonkunst, Suhrkamp Verlag, Frankfurt am Main 1974, 40. Podobno razmišlja dobro desetletje kasneje (1919) Paul Bekker v svojem spisu o Novi glasbi (Neue Musik): "Za Novo glasbo je karaktertistično, da se ne oklepa že obstoječih zakonov, temveč začenja s kritiko njihovih temeljev."BEKKER, PAUL, Neue Musik, Deutschen Verlags-Anstalt, Stuttgart in Berlin 1923, 95.

3 Po prvi svetovni vojni je Anton Lajovic storil izjemno nevaren mnenjski »korak" naprej; sodil je, da je za Slovence v glasbi nemških mojstrov smrtno nevaren strup tevtonske tujosti, zaradi česar je ne gre samo pustiti vnemar, temveč jo je treba na koncertnih odrih južno od Karavank tudi radikalno zatreti. GRDINA, IGOR, »Hugo Wolf in Josip Ipavec - skica primerjalne biografije«, Ur. ČEPIN, BRANKO, Hugo Wolf - sodobniki in nasledniki, Društvo Huga Wolfa Slovenj Gradec, Slovenj Gradec 2001, 104. Glej tudi: KURET, PRIMOŽ, Umetnik in družba, Državna založba Slovenije, Ljubljana 1988, 115.

4 V Češkoslovaškem glasbenem leksikonu oseb in institucij (ČERNUŠÁK, GRACIAN, »Procházka, Josef«, Ur. GRACIAN ČERNUŠÃK in VLADIMÍR HELFERT, Československý hudebni slovnik osob a institucí, Státní hudební vydavatelství, Praga 1965, 371) je slednji naveden kot Josef Procházka. Pri uporabi imena Josip oziroma Jožef (RUDOLF, ANDREJKA, »Procháska, Jožef «, Ur. FRANCE KIDRIČ in FRANC KSAVER LUKMAN, Slovenski biografski leksikon, Zadružna gospodarska banka, Ljubljana 1933-1952, 585) gre torej za slovenski izpeljanki iz češkega imena Josef.

5 Po treh letih študija orgel pri Josefu Klički in klavirja pri Josefu Jiráneku (BRANBERGER, JOHANN, Das Konservatorium für Musik in Prag, Verlag des Vereines zur Beförderung der Tonkunst in Böhmen, Praga 1911, 350) je v študijskem letu 1896/97 končal s poukom kompozicije pri Antonínu Dvořáku. Z Dvořákom se je Procházka sestajal ne le kot z učiteljem, temveč tudi v prijateljskem okolju glasbenega društva Kluba mladih v Pragi. Dvořák je podpiral Procházkina ustvarjalna prizadevanja in mu za časa študija kompozicije, kot član strokovnega sveta omenjenega društva, omogočil skladateljsko štipendijo Češke akademije znanos- 
bene matice v Ljubljani, na kateri je med letoma 1898 in 1908 poučeval klavir in kompozicijo. ${ }^{6}$ Svoje pa je verjetno prispevala tudi naklonjenost uredništva Novih akordov. Tako je mogoče že v uvodni številki omenjene revije zaslediti kar dve Procházkini kompoziciji: Nokturno za violino in klavir ter samospev Kaj bi te vprašal?,7 na urednikovo izrecno željo pa je uredništvu že naslednji dan po objavi poslal še dve skladbi za violino in klavir. ${ }^{8}$

Urednik revije Gojmir Krek je Procházko ob objavi njegove prve kompozicije v Novih akordih pozdravil kot dobrodošlega sodelavca ter napol v šali pripomnil, da je posebno v zadnjem obdobju mogoče opaziti »čudno prikazen češko-slovenskih muzikov. «9 Zanimivo se zdi, da so bile med več kot 60 kompozicijami, ki so konca meseca junija 1901 prispele v uredništvo, vse Procházkine kompozicije, ki jih je poslal v objavo v prvem letniku tudi objavljene. ${ }^{10}$ Simona Moličnik zapiše: »Za raznovrstnost objavljenih skladb je Krek poskrbel z dodatnimi dopisi tistim skladateljem, ki so bolje obvladali kompozicijsko-tehnične probleme. Ker takih med domačimi ustvarjalci ni bilo veliko, je skušal pridobiti tudi druge slovanske ustvarjalce. «11 Med njimi prevladu-

ti in umetnosti. ČERNUŠÁK, GRACIAN, "Procházka, Josef", Ur. GRACIAN ČERNUŠÁK in VLADIMÍR HELFERT, Československý hudební slovnik osob a institucí, Státní hudební vydavatelství, Praga 1965, 371-372.

6 Da je bila konkurenca za omenjeno mesto res velika, dokazuje zavrnitev Romea Finkeja (1868-1938), Procházkinega najresnejšega protikandidata, ki je kasneje postal eden najuglednejših klavirskih pedagogov na državnem konservatoriju v Pragi ter prvi direktor Nemške akademije za glasbo in upodabljajočo umetnost v Pragi. Zdi se, da je imel Procházka pri pouku na ljubljanski matičini šoli sprva precej težav. Tako je 14. februarja 1900 od odbora Glasbene matice prejel sklep o prekinitvi delovnega razmerja: »Odbor je sklenil na seji 14. februarja 1900, da Vam odpoveduje službo s 15 . avgustom $1900 \mathrm{~s}$ pristavkom, da bo koncem šolskega leta 1900 pripravljen eventualno ponovno z Vami skleniti pogodbo, če bodo učni uspehi ob koncu šolskega leta popolnoma zadostovali." Glasbena zbirka NUK, Glasbena matica Ljubljana, Kronika, Dopis odbora Glasbene matice, Ljubljana, 14. februar 1900. Kljub nasprotovanju Mateja Hubada, ki je Procházko kritiziral z besedami "za učitelja se do sedaj ni izkazal; višji razredi potrebujejo izvrstnega pianista" (BUDKOVIČ, CVETKO, Razvoj glasbenega šolstva na Slovenskem I, Znanstveni inštitut Filozofske fakultete, Ljubljana 1992, 265), je bil 22. oktobra 1903 imenovan za rednega profesorja. Odbor Glasbene matice v Ljubljani je Procházki šele kasneje priznal nesporne pianistične kvalitete z izjavo: »Prof. [Profesor] g. [gospod] Josip Procházka je od 15. oktobra 1898 do 1. julija 1908 deloval kot klavirski učitelj na zavodu. Kot velik strokovnjak ogromnega znanja je posvetil vso svojo skrb glasbeni vzgoji izročene mu mladine." Glasbena zbirka NUK, Glasbena matica Ljubljana, Kronika, Uradno potrdilo odbora o službovanju Josipa Procházke, Ljubljana, 13. januar 1928.

7 PROCHÁZKA, JOSIP, »Nokturno«, »Kaj bi te vprašal?«, Ur. KREK, GOJMIR, Novi akordi 1 (1901) 1, L. Schwentner, Ljubljana 1901, 12-14, 20. Skladbama je Procházka pripisal posvetili. Nokturno je posvečen "prijatelju prof. [profesorju] Št. Suchému«, samospev Kaj bi te vprašal? pa »gospodični Vidi Verbičevi«. Procházka je edini med skladatelji, ki so objavili skladbe v uvodni številki Novih akordov, objavil več kot eno kompozicijo.

8 Glasbena zbirka NUK, Notni arhiv Novih akordov, Procházka Josip, Elegie pro housle a klavir (Elegijo za violino in klavir), op. 8 ter Nokturno pro housle a prův. [průvod] klavíru (Nokturno za violino in spremljavo klavirja), op. 2.

9 ŠPENDAL, MANICA, Razvoj in značilnosti slovenskega romantičnega samospeva, Obzorja, Maribor 1981, 65. Da je moral biti Procházka Kreku posebno blizu kaže tudi naslednji, ne nepomemben podatek. Slednji je namreč izbrane skladatelje zaprosil za njihove fotografije, ki so jih nato v Novih akordih enotno reproducirali v likovni obliki. Med šestimi »izbranci« (Benjaminom Ipavcem, Ristom Savinom, Franom Gerbičem, Viktorjem Parmo in Gojmirom Krekom) najdemo tako v drugem letniku revije, v vsem svojem sijaju, tudi Josipa Procházko (NA II/1902-03, 5. zv.).

10 Med njimi najdemo: Nokturno (I) za violino in klavir (NA I/1901-02, 1. zv.), samospev Kaj bi te vprašal? (NA I/1901-02, 1. zv.), Elegijo za violino in klavir (NA I/1901-02, 1. zv.), Vabilo za moški zbor (NA I/1901-02, 2. zv.), Barcarolo za klavir (NA I/1901-02, 4. zv.), Nokturno (II) za violino in klavir (NA I/1901-02, 4. Zv.), Romanco za klavir (NA I/1901-02, 5. Zv.) in samospev Zvezde žarijo (NA I/1901-02, 6. zV.).

11 MOLIČNIK ŠIVIC, SIMONA, Notni in pisni arhiv Novih akordov 1901-1914, Magistrska naloga, Mentor: prof. dr. KATARINA BEDINA, Oddelek za muzikologijo Filozofske fakultete Univerze v Ljubljani, Ljubljana 2002, 13. Glej tudi: MOLIČNIK, SIMONA, Novi akordi: zbornik za vokalno in instrumentalno glasbo, Slovenska matica in Slovensko muzikološko društvo, Ljubljana 2006, 19-22. 
jejo češki skladateljski imigranti: Anton Foerster, Emerik Beran, Karl Hoffmeister, Julij Junek in Josip Procházka. ${ }^{12} \mathrm{~K}$ sodelovanju je torej povabil slovenske kot tudi češke in hrvaške, skratka slovanske ustvarjalce, ki so skoraj vsi z veseljem sprejeli urednikovo ponudbo in mu za objavo poslali nekaj svojih kompozicij. ${ }^{13}$ Krog "novoakordovcev« se je tako hitro in predvsem premišljeno širil. Kot po pravilu pa med njimi ni bilo nekaterih nemških skladateljskih imen, skladbe progermanskih političnih simpatizerjev pa so bile prej izjema kot pravilo. ${ }^{14}$ Kljub temu, da so bili Novi akordi vse od leta 1904 urejani z varne dunajske razdalje, so ob pisanju dopisov tako eni kot drugi praviloma "pozabili« drugi na druge. ${ }^{15}$ Kako torej razumeti "resnično željo uredništva, da naj bi se pod praporom Novih akordov našli vsi skladatelji katere koli umetniške struje?«16 Če lahko kot nadvse pomembno pozdravimo Krekovo zahtevo po kompozicijskotehnični neoporečnosti pa imamo lahko več težav z njegovim razumevanjem napredka v funkciji utrjevanja nacionalne samobitnosti. ${ }^{17}$ Mar niso bila prizadevanja za slovensko glasbeno avtonomnost v začetku 20. stoletja že povsem neaktualna in so na

12 Skupno je bilo od 44 poslanih kompozicij češke skladateljske imigracije na Slovenskem, v Novih akordih objavljenih 41 skladb: Anton Foerster (2), Emerik Beran (2), Karl Hoffmeister (4), Julij Junek (4) in Josip Procházka (29). Glasbena zbirka NUK, Notni arhiv Novih akordov.

13 Med 43 poslanimi kompozicijami hrvaških ustvarjalcev je bilo v Novih akordih objavljenih zgolj 19 skladb. $\mathrm{S}$ po največ kompozicijami med njimi izstopata Vjekoslav Rosenberg-Ružić (12) in Ivan Zajc (3). Pozivi ustvarjalcem z drugih področij kasnejše skupne države niso znani. Glasbena zbirka NUK, Notni arhiv Novih akordov.

14 V podobno nezavidljivem položaju so bili na drugi strani slovenski skladateljski disidenti. Okoli leta 1900 je bil v Gradcu umetnik lahko obsojen na propad samo zato, ker so mu vzklikali Slovani. Josip Ipavec se je na primer bal, da bodo njegovi rojaki ob premieri Princese Vrtoglavke v štajerskem glavnem mestu z glasnim izražanjem svojega navdušenja vznejevoljili Nemce. GRDINA, IGOR, »Hugo Wolf in Josip Ipavec - skica primerjalne biografije«, Ur. ČEPIN, BRANKO, Hugo Wolf - sodobniki in nasledniki, Društvo Huga Wolfa Slovenj Gradec, Slovenj Gradec 2001, 108.

15 KURET, PRIMOŽ, Deutsches Kulturschaffen in Krain vor dem Ersten Weltkrieg, Ur. LOOS, HELMUT, Deutsche Musik im Osten, Gudrun Schröder Verlag, Sankt Augustin 1997, 533-534.

16 KREK, GOJMIR, Novi akordi, Ur. AŠKERC, ANTON, Ljubljanski zvon 21 (1901), Narodna tiskarna, Ljubljana 1901, 576. Krek je pred prvo svetovno vojno med drugim pisal tudi o glasbi Huga Wolfa, ki da je takšna da "[...] se večini slovenskega glasbenega občinstva še sanja ne." KREK, GOJMIR, Hugo Wolf in Slovenci, Ur. KREK, GOJMIR, Novi akordi 9 (1910) 3, L. Schwentner, Ljubljana 1910, 20. Lucijan Marija Škerjanc je še ostreje orisal glasbene razmere na Slovenskem na prelomu stoletja: »[...] naše kompozicije te dobe predočujejo glasbeno življenje v idiličnem in nekoliko zatohlem ter dolgočasnem vzdušju zahajajočega malomeščanstva [...] niti list se ne gane spričo burij, ki so prav tedaj pihale čez livade glasbene umetnosti po svetu.« Vendar tudi dodaja: »Romantika Gartenlaube-sloga je bil pač skrivaj gojeni in od miljonov kulturnih ljudi realizirani ideal ob začetku novega stoletja [...] zato se ni čuditi, da najdemo odsev takšnih stremljenj tudi v naši glasbi one dobe. ŠKKERJANC, LUCIJAN MARIJA, Anton Lajovic, Slovenska akademija znanosti in umetnosti, Ljubljana 1958, 20. Skladb Josipa Ipavca v katerih je slednji omenjeni »Gartenlaube stil očitno presegel Škerjanc najverjetneje ni poznal. Vendar mu tega ne gre pretirano zameriti, saj so bile na primer v Novih akordih objavljene zgolj 3 Ipavčeve kompozicije. Igor Grdina denimo meni, da je prav Josip Ipavec ena najbolj tragičnih osebnosti med takratnimi slovenskimi skladatelji. GRDINA IGOR, Predgovor, Ur. GRDINA, IGOR, Josip Ipavec in njegov čas, Založba ZRC SAZU, Ljubljana 2000, 7-9. Glej tudi: GRDINA, IGOR, Josip Ipavec zwischen Musik, Literatur und Medizin, Ur. PETER ANDRASCHKE in EDELGARD SPAUDE, Kunst-Gespräche: musikalische Begegnungen zwischen Ost und West, Rombach, Freiburg im Breisgau 1998, 140.

17 Kljub Krekovi jasno izraženi modernistični paroli z geslom "Naprej« in njegovi trditvi, da je "ravno takih skladb treba spraviti na dan, če se hoče res koristiti razvoju slovenske glasbene literature« (KREK, GOJMIR, Novi akordi, Ur. AŠKERC, ANTON, Ljubljanski zvon 21 (1901), Narodna tiskarna, Ljubljana 1901, 576) je od 5. Kogojevih skladb, ki so bile poslane uredništvu, Krek v Novih akordih objavil le mešani zbor Trenotek (NA XIII/1913-14, 4. zv.). Glasbena zbirka NUK, Notni arhiv Novih akordov. Krek jih je zavrnil, češ da so sicer zelo nova, izvirna, vendar ne dovolj izdelana. Glede skrajno slabo čitljivega rokopisa pa zapisal: »Priporočamo [Vam] več spoštljivosti napram očem urednika-mučenika."In dodal: „Takih nemarno pisanih rokopisov v bodoče ne preberemo več. "KREK, GOJMIR, Listnica uredništva, Ur. KREK, GOJMIR, Novi akordi 12 (1913) 5-6, L. Schwentner, Ljubljana 1913, 60. 
primer skladatelji samospevov že ustvarili začetke lastne tradicije? Obstajali so torej pogoji, ki ponujajo "zaščitenost«, »omogočajo afirmacijo doživljajskosti« ter »dopuščajo varen vstop v osebni glasbeni svet«. ${ }^{18}$

Novi akordi so do začetka izhajanja književne priloge leta 1910 objavili 70 samospevov, ${ }^{19} 6$ duetov in 7 četverospevov. Pri tem je urednik načrtno poskrbel, da objavljene skladbe: »Ne zahtevajo od pevcev preobsežnih glasov [glasovnih razponov] in visoko izobražene [kultivirane] vokalne tehnike. ${ }^{20} \mathrm{~V}$ navadi je namreč bilo, da se je tovrsten repertoar prepeval po privatnih domovih in na manjših veselicah. Da so bile skladbe »lahkotnejšega« žanra tiste, ki so pritegnile največ pozornosti občinstva dokazujejo kompozicije Viktorja Parme, ki so bile v slovenski javnosti tako priljubljene, da si je Krek z njimi pomagal celo pri reklamiranju Novih akordov. ${ }^{21}$

Razen v zborovski produkciji je Procházka po številu objav, v vseh drugih kompozicijskih zvrsteh povsem v vrhu ustvarjalcev Novih akordov.22 11 med 29 v Novih akordih objavljenimi opusi kaže, da je bila zanj vokalna miniatura vseskozi v žarišču zanimanja. Kljub temu odmevnejše recepcije Procházkini samospevi niso doživeli. Posnetki razen nekaj tistih na precej »načetih" magnetofonskih trakovih, ki jih hranijo v ljubljanskem radijskem arhivu, niso na voljo. ${ }^{23}$ Tudi najvidnejši razpravljalci o slovenskem samospevu Procházke večinoma ne obravnavajo. Marij Kogoj ga ne omenja v svojem sestavku O razvoju slovenskega samospeva (1922), ${ }^{24}$ skladatelja pa pogrešamo tudi med ustvarjalci samospevov v Zborniku slovenskih samospevov (1953)25 Vilka Ukmarja in v Lipovškovi razpravi Sodobni slovenski samospev (1957)26. Zgolj Manica Špendal mu v svoji monografiji Razvoj in značilnosti slovenskega romantičnega samospeva (1981)

18 BERGAMO, MARIJA, "Življenja zmožni« zgodnji samospevi Lucijana Marije Škerjanca, Ur. PRIMOŽ KURET in JULIJAN STRAJNAR, Glasba in poezija, Slovenski glasbeni dnevi, Ljubljana 1990, 194.

19 Med njimi najdemo tudi enega za glas in orgle. Glasbena zbirka NUK, Notni arhiv Novih akordov.

20 MOLIČNIK ŠIVIC, SIMONA, Notni in pisni arhiv Novih akordov 1901-1914, Magistrska naloga, Mentor: prof. dr. KATARINA BEDINA, Oddelek za muzikologijo Filozofske fakultete Univerze v Ljubljani, Ljubljana 2002 , 28.

21 V pismu Lavoslavu Schwentnerju zapiše: »Iz Parmovih koračnic, valčkov in polk veje tista očarljiva kantabilnost in narodno buditeljski značaj, ki zlahka najde pot do poslušalcev." Arhiv Republike Slovenije, Pismo Gojmira Kreka Lavoslavu Schwentnerju, AS 158, 3. junij 1903.

22 Na Procházkine skladateljske kvalitete kaže tudi dejstvo, da je Krek objavil vse Procházkine kompozicije, ki mu jih je sledji poslal v objavo. Po številu klavirskih kompozicij tako za eno skladbo zaostaja le za Emilom Adamičem, ki je s 14. kompozicijami z naskokom prvi, med skladatelji komornih kompozicij pa je s tremi skladbami za violino in klavir celo na prvem mestu. Tudi po številu objavljenih samospevov je povsem $\mathrm{v}$ vrhu ustvarjalcev, saj zaostaja le za Gojmirom Krekom, ki je v času izhajanja zgolj glasbenega dela Novih akordov objavil 17 samospevov. S precejšnjim zaostankom Procházki z 11. samospevi sledijo Emil Adamič (7), Anton Lajovic (5), Oskar Dev (3), Viktor Parma (2) in številni drugi s po enim samospevom. Glasbena zbirka NUK, Notni arhiv Novih akordov.

23 Podobna je usoda ponatisov Procházkinih kompozicij z izjemo samospeva Kaj bi te vprašal?, ki je izšel v zbirki Zgodnji slovenski samospevi Edicij Društva slovenskih skladateljev. PROCHÁZKA, JOSIP, Kaj bi te vprašal?, Ur. MIHEVC, MARKO, Zgodnji slovenski samospevi, št. 1777, Edicije Društva slovenskih skladateljev, Ljubljana 2005, 118-119.

24 Med češkimi skladateljskimi imigranti na Slovenskem (Nedvědom, Foersterjem, Hoffmeistrom in Michlom), ki jih v članku omenja Kogoj, ne najdemo Procházke. KOGOJ MARIJ, Dom in svet, Ur. MERHAR, ALOJZIJ, 35 (1922), 282-285.

25 UKMAR, VILKO, Slovenski samospev od pričetka do moderne dobe, Ur. UKMAR, VILKO, Zbornik slovenskih samospevov od pričetka do moderne dobe I, Edicija Društva skladateljev Slovenije, Ljubljana 1953, 3-9.

26 LIPOVŠEK, MARIJAN, Sodobni slovenski samospev, Ur. MARIJAN LIPOVŠEK in MATIJA BRAVNIČAR, Slovenska glasbena revija 4 (1957), Društvo slovenskih skladateljev, Ljubljana 1957, 10-12. 
nameni nekaj omemb. ${ }^{27}$ Kljub temu se zdi, da Procházkini samospevi doslej še niso bili ustrezno ovrednoteni. Omenjeni samospevi so z izjemo kasnejših na češka besedila, ${ }^{28}$ ki jih je zdi se napisal kmalu po začetku njegovega poučevanja klavirja na srednji šoli državnega konservatorija v Pragi, edini v skladateljevem opusu. ${ }^{29}$ Gre torej Procházkino konstantno snovanje samospevov na Slovenskem razumeti predvsem v luči Krekovih prizadevanj po »novejši« generaciji slovenskega samospeva ali morda bolj v želji po zadostitvi trenutnih recepcijskih potreb poslušalstva?

Zdi se, da se Procházka pri komponiranju samospevov ni podrejal trenutnemu okusu poslušalstva, saj o javnih izvedbah njegovih samospevov skorajda ni podatkov. ${ }^{30}$ Vsekakor pa ob naraščujoči produkciji slovenskega samospeva ne gre prezreti literarnega vpliva na Procházkino komponiranje samospevov. Razvoj slovenskega samospeva je bil v začetku 20. stoletja kar najtesneje povezan z razcvetom slovenskega pesništva. Slovenska pesniška moderna, ki je pripadala isti generaciji kot Procházka (naj omenimo samo v sedemdesetih letih rojene Ketteja, Murna in Župančiča) je navdihnila mnoge ustvarjalce samospevov. Tudi v literarnem oziru je bila torej idejna orientacija Novih akordov več kot jasna. Tako s stališča narodno zavedne usmeritve k slovenščini skoraj ni bilo mogoče, da bi skladatelji izbirali med pesniškimi besedili v drugih jezikih. ${ }^{31}$

Med enajstimi skladateljevimi samospevi objavljenimi v Novih akordih najdemo zgolj samospeve za višji glas (sopran oziroma tenor), ki v nobeni izmed skladb ni nedvoumno določen. Čeprav kratko ustvarjalno obdobje skladatelju ni dopustilo večjih kompozicijsko-tehničnih nihanj, je mogoče v posameznih kompozicijah izpostaviti določene karakteristične odmike. Tako se že v prvem samospevu z naslovom Kaj bi te vprašal?32 iz leta 1901 pojavijo nekatere nekonvencionalne rešitve, ki izstopajo iz sicer

27 ŠPENDAL, MANICA, Razvoj in značilnosti slovenskega romantičnega samospeva, Obzorja, Maribor 1981, 62, 65, 141.

28 Procházkini samospevi objavljeni v Novih akordih nosijo zgodnje številke opusov, tako je mogoče sklepati, da so samospevi op. 13 (Čtyři dvojzpěvy), op. 22 (Občan republiky, Pochod Československých vojáků, Brigádm, Žijem jen jednou, Ta čistá země, Vlaj, naše vlajko!, Nový pokolský pochod) idr. (op. 61 in 74), med katerimi so bili nekateri izdani pri založniški hiši Urbánek v Pragi, nastali v kasnejšem obdobju. ČERNUŠÁK, GRACIAN, »Procházka, Josef", Ur. GRACIAN ČERNUŠÁK in VLADIMÍR HELFERT, Československý hudební slovnik osob a institucí, Státní hudební vydavatelství, Praga 1965, 372.

29 Nedosledno, ponekod dvojno številčenje opusov, otežuje izdelavo natančnejšega seznama Procházkinih kompozicij. V skladateljskem opusu, ki obsega nekaj čez 100 enot prevladujejo klavirske kompozicije s poetičnimi miniaturami, stiliziranimi plesi in etudami. Tem sledijo komorne in vokalne kompozicije, orkestralne skladbe, napisal pa je tudi manjše število vokalno-instrumentalnih kompozicij. Ibidem, 372. Glej tudi: »Pozůstalnost Josefa Procházky« v mapi »Procházka, Josef« arhiva Glasbene zbirke NUK.

30 Če so bile izvedbe Procházkinih klavirskih kompozicij na produkcijah Glasbene matice pogoste, so bili njegovi samospevi redkeje izvajani. V koncertnih listih zasledimo zgolj izvedbe samospevov Zvezde žarijo, Tak si lepa... in Poslednja noč. Vladimir Foerster v kritiki koncerta Glasbene Matice meni, da omenjene samospeve "preveva vseskozi neka miloba slovensko čuteče duše in da jim ta miloba daje prikupljivo kantileno pri glasbeno strogo dovršenem konceptu." FOERSTER, VLADIMIR, Glasba, Ur. ZBAŠNIK, FRAN, Ljubljanski zvon 23 (1903), Narodna tiskarna, Ljubljana 1901, 572.

31 Tako je na primer Gojmir Krek nemško besedilo sprva dvojezičnega (slovensko-nemškega) samospeva Pastirica (Das Hirtenmädchen) Emila Hochreiterja, ki mu je bil poslan za objavo v Novih akordih, prečrtal in kot urednik dovolil objavo zgolj slovenskega besedila (NA XIII/1914, 1.-2. zv.). Glej samospev Pastirica v notnem arhivu Novih akordov Glasbene zbirke NUK pod inventarno številko 187/1955.

32 Samospev Kaj bi te vprašal? (NA I/1901-02, 1. zv.) na besedilo Antona Aškerca je skladatelj napisal 10. aprila 1901. Samospev je posvečen "gospodični Vidi Verbičevi«. Glej samospev Kaj bi te vprašal? v notnem arhivu Novih akordov Glasbene zbirke NUK pod inventarno številko 362/1955. 
tradicionalnejših kompozicijsko-tehničnih okvirov. Skladatelj na primer v taktih 5 do 9 kljub sicer prevladujoči harmonski vpetosti v podstat osnovne tonalitete G-dura, karakteristični pedalni ton ob doseganju viška zamenja s kromatično linijo v basu. (Primer 1)
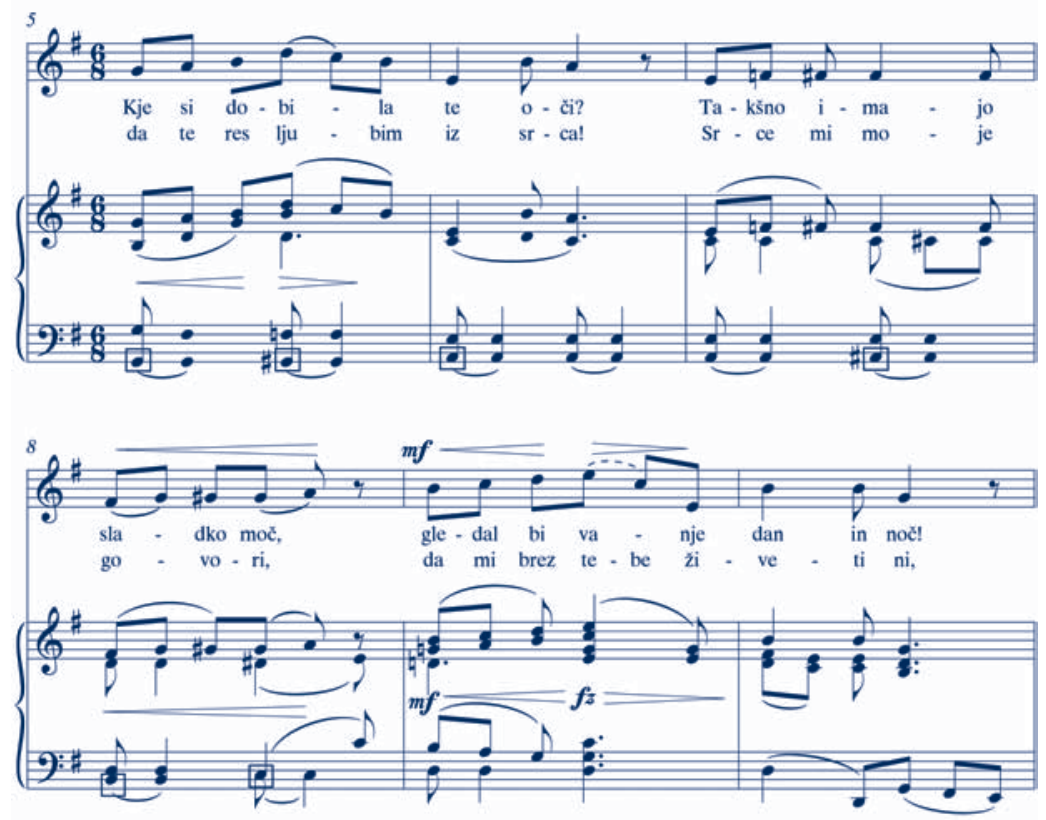

Primer 1: Kaj bi te vprašal? (1901), takti 5-11.

Motivične in harmonske reminiscence sicer nakazujejo tridelno pesemsko obliko, ki pa jo skladatelj z neprestanim nizanjem dvotaktij ob uglasbitvah posameznih verzov uspešno zabriše. Prevladujoča poetska komponenta, ki skladatelju narekuje preoblikovanje tradicionalnih formalnih okvirov je znova opazna $\mathrm{v}$ drugem samospevu $\mathrm{z}$ naslovom Zvezde žarijo 33 iz leta 1902. V omenjenem samospevu je skladatelj konvencionalne lirične podobe Aškerčeve balade Kaj bi te vprašal? zamenjal z Župančičevo ljubezensko liriko iz zbirke Čaša opojnosti (1899), ki je skladatelju po svoji idejni in tematski naravnanosti posebno ustrezala. V njegovih samospevih je tako mogoče zaslediti kar štiri Župančičeve, tri Aškerčeve, dve Medvedovi in po eno Jenkovo ter Stefanovo ${ }^{34}$ besedilno predlogo.

Procházka se je torej pri izbiri besedil za uglasbitve odločal večinoma za pesniške stvaritve visoke umetniške vrednosti. Nadvse presenetljivo se zdi skladateljevo dobro poznavanje slovenskega jezika. Kljub "problematičnosti« češkega naglaševanja na prvem zlogu, ${ }^{35}$ ki se pogosto razlikuje od naglasnih postavitev v slovenskem jeziku, se v

33 Samospev Zvezde žarijo (NA I/1901-02, 6. zv.) z oznako op. 7, št. 3 je posvečen "gospodični Miri Devovi«.

34 Manj znano je, da se je znameniti fizik Jožef (Josip) Stefan (Štefan) v dijaškem in študentskem obdobju s precejšno vnemo loteval tudi pesniških poizkusov. V letih 1850-58 je pisal domoljubne, narodnobuditeljske, prigodne, razpoloženjske, ljubezenske in razmišljujoče pesmi. SANDI SITAR in JANEZ STRNAD, "Stefan, Jožef«, Ur. VOGLAR, DUŠAN, Enciklopedija Slovenije, 12. zvezek, Ljubljana 1998, 299. 
Procházkinih uglasbitvah vselej kaže dosledno upoštevanje zgradbe verza in besednega akcenta. Da je znal skladatelj prisluhniti vsebinskemu značaju posameznega teksta ter ga oblikovati v vseh njegovih odtenkih je lepo razvidno iz leta 1903 napisanega samospeva Bolne rože ${ }^{36}$. Župančičev ciklus Bolne rože je vzbudil pozornost kar petnajstih skladateljev iz kroga Novih akordov. Slednji z metaforiko cvetja in pomladi ter prevladujočo žalostjo poje o oboževani izvoljenki in bolečini zaradi njene prevare, pa o njegovem odpuščanju in ponovnem hrepenenju. ${ }^{37}$ Zdi se, da je tej vrsti ljubezenskoizpovedne lirike samospev s svojo subtilnostjo najbolj ustrezal. Procházka je pesnikov izraz glasbeno okrepil s pretehtanim izborom kompozicijskih sredstev. Prevladujejo dominantne harmonije, mestoma alterirani akordi, značilno je približevanje dura in mola (modulacije v subdominantno in dominantno paralelo A-dura) ter kljub še vedno izraziti tonikalni podstati vse večji odmiki od tradicionalnih kadenčnih odnosov. Harmonija ni intenzivna $\mathrm{v}$ poznoromantičnem smislu, prej bi ji pripisali barvitost in mehkobo nekaterih impresionističnih postopov, četudi je mestoma plod premišljene rabe v službi ekspresije. Tudi v tem samospevu se zdi harmonija tisti glasbeni element, ki se odziva na izrazne odtenke pesemskega razpoloženja in usmerja glasbeni tok. Tako tudi dinamika, agogika in formalna oblika izredno tankočutno sledijo skupnemu razpoloženju. V odnosu glas - klavir postaja slednji vedno samostojnejši, saj ni več le v funkciji harmonske podpore pevski liniji v raznih oblikah akordske figuracije, temveč je prav tako nosilec glasbene vsebine. Z namenom, da vsebinsko nadaljuje določeno razpoloženje, prinaša motivično gradivo. (Primer 2)
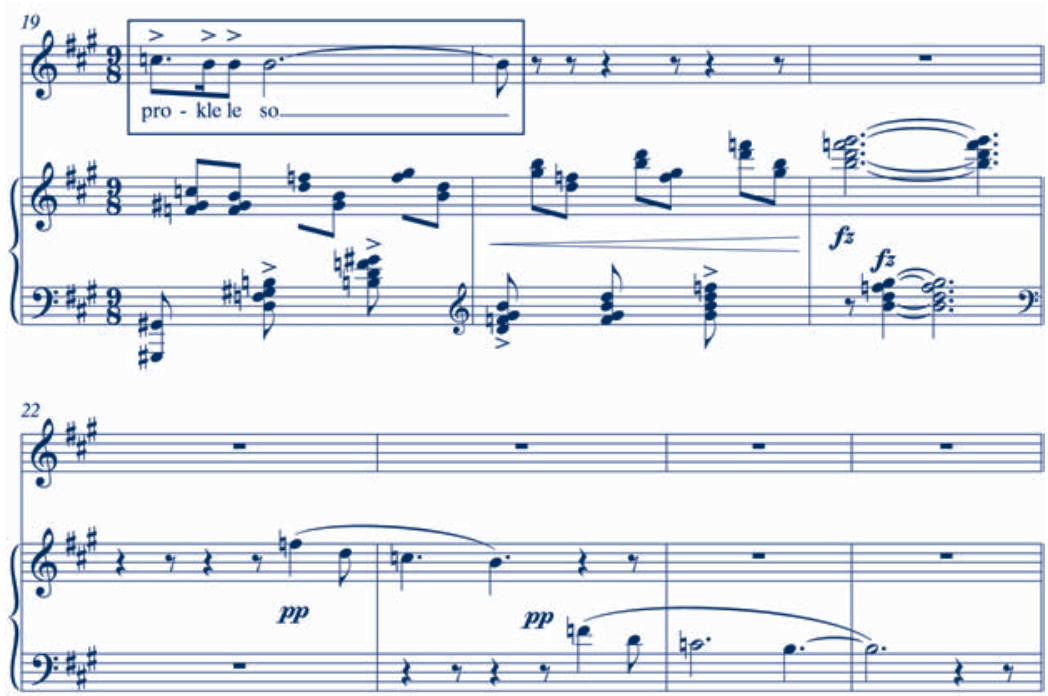

Primer 2: Bolne rože (1903), takti 19-26.

35 SMACZNY, JAN, Dvořák's Cypresses: A Song Cycle and its Metamorphoses, Ur. KLAUS DÖGE in PETER JOST, Dvořák-Studien, B. Schott's Söhne, Mainz 1994, 55-60.

36 Glej samospev Bolne rože (NA II/1902-03, 5. zv.).

37 MAHNIČ, JOŽA, Kaj v Župančičevi liriki je pritegovalo skladatelje?, Ur. PRIMOŽ KURET in JULIJAN STRAJNAR, Glasba in poezija, Slovenski glasbeni dnevi, Ljubljana 1990, 70. 
Tudi v samospevu Tak' si lepa... ${ }^{38}$ na besedilo Simona Jenka, ki je bil prvič objavljen že v Gerbičevi Glasbeni zori leta 1899, klavirski part s svojo domiselno gradnjo razkriva skladateljevo hotenje po enakovrednosti vokala in inštrumentala. Kot da bi hotel gospodični Jarmili Gerbič, ki ji je leta 1903 v Novih akordih posvetil omenjeni samospev, prikazati vse svoje nesporne pianistične kvalitete. Tako Vladimir Foerster ob izidu samospeva v Ljubljanskem zvonu zapiše: "Posebno samospev Tak’ si lepa iz katerega odseva sladko razvneta melodija nudi posebno mnogo za pianiste. ${ }^{39}$

Predvsem leta 1903 napisana samospeva Poslednja noč 40 na besedilo Antona Aškerca in O ljubica...41 na besedilo Otona Župančiča izkazujeta skladateljevo tendenco po simbiozi tradicionalnejših z novejšimi kompozicijsko-tehničnimi postopki. Omenjena samospeva tako s pojavom polifonih elementov, harmonskimi alteracijami in predvsem prepletom pesemske in variacijske oblike sledita t.i. dunajskemu modelu, kot ga je mogoče zaslediti v zgodnjih samospevih Johannesa Brahmsa konec 60. in v začetku 70. let. ${ }^{42} \mathrm{~V}$ osnovi periodično gradnjo skladatelj skladno s pomenskimi odtenki besedila varirano preoblikuje in se tako oddalji od formalne zaokroženosti. (Primer 3)
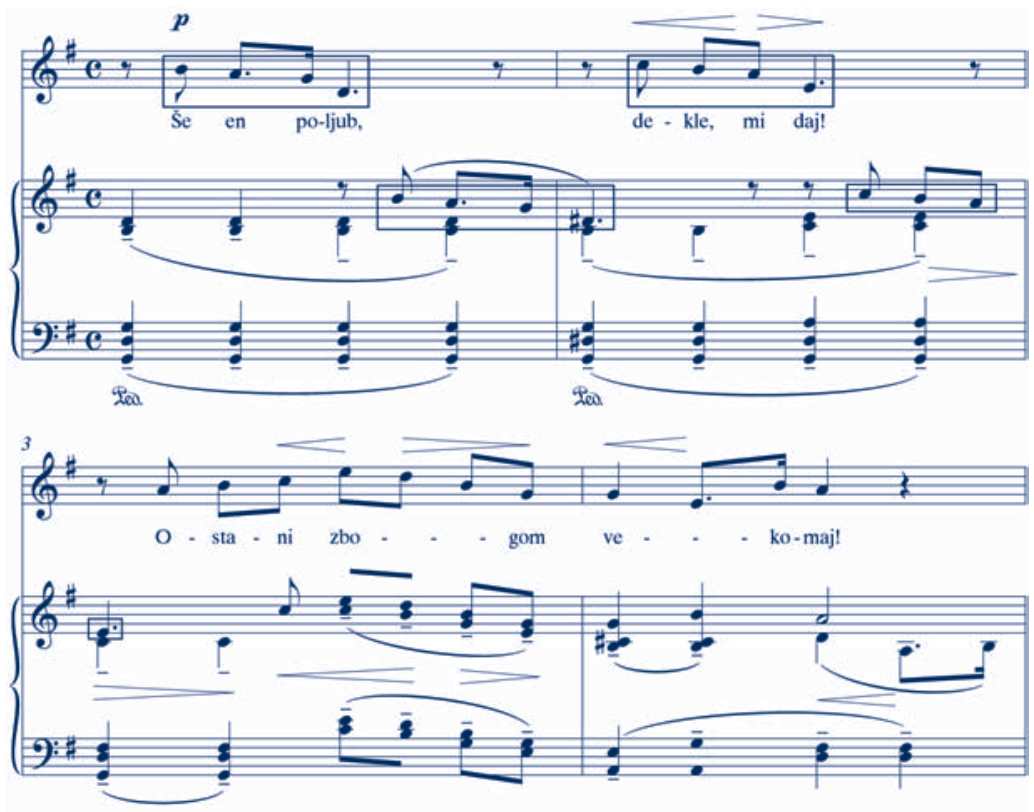

Primer 3: Poslednja noč (1903), takti 1-5.

38 Glej samospev Tak' si lepa... (NA III/1903-04, 1. zv.).

39 FOERSTER, VLADIMIR, Glasba, Ur. ZBAŠNIK, FRAN, Ljubljanski zvon 23 (1903), Narodna tiskarna, Ljubljana 1901, 572. V Ljubljanskem Zvonu so v rubriki Glasba redno izhajale ocene posameznih številk revije Novi Akordi, večinoma izpod peresa Vladimirja Foersterja. Skupni imenovalec kritiških odzivov na Procházkina dela je vsekakor pozitiven.

40 Glej samospev Poslednja noč (NA II/1902-03, 5. zv.).

41 Glej samospev O ljubica... (NA II/1902-03, 6. zV.).

42 JOST, PETER, Brahms und das deutsche Lied des 19. Jahrhunderts, Ur. JOST, PETER, Brahms als Liedkomponist, Franz Steiner Verlag, Stuttgart 1992, 36-37. 
Z uporabo tradicionalnejših kompozicijsko-tehničnih sredstev pa se je znal skladatelj približati tudi bolj diletantskim pesniškim poizkusom kot leta 1904 ob uglasbitvi samospeva Pesem ${ }^{43}$ na besedilo Jožefa Stefana. Periodično in relativno simetrično grajena melodika je v omenjenem samospevu logično povezana z besedilom. Tudi ritmika je $\mathrm{v}$ glavnem enostavna in se tesno sklada z besedilno metriko. Odločnejši odmik od klasicistično romatične vokalne miniature "Mendelssohnovega tipa", k novoromantičnemu ozvočenju pesnikove besede je mogoče zaznati v samospevu Japonski motiv ${ }^{4}$ iz leta 1904 na Župančičevo besedilo. Skladatelj razpoloženja pesmi nikoli ne zavrže in ne preglasi. Razen nekaterih izjem ni pretiravanj ne v sentimentalnost, ne v dramatičnost. Zdi se, da je bila ljubezenska lirika skladatelju v kasnejših samospevih zgolj začetni impulz, ki je spodbudil osnovno glasbeno vzdušje. Glasbena interpretacija namreč zajema mnogo širše izpovedno območje, besedilo pa postane le osnova za razvite glasbene ideje. Čeprav je melodika primarni parameter glasbenega domisleka, njen izraz v samospevih Sneg pada ${ }^{5}$ iz leta 1904 na besedilo Antona Aškerca in Hrepenenje ${ }^{46}$ iz leta 1906 na besedilo Antona Medveda obarva spretno vodena poznoromantična harmonija. Z nenavadno bogato harmonsko gradacijo - pri pestri uporabi harmonskih zvez, značilnih za svobodni harmonski stavek poznoromantičnega obdobja - je Procházka v omenjenih samospevih poglobil smisel Medvedovega in Aškerčevega besedila $v$ pravo dramsko izpoved. Tonalnost je močno razširil z uporabo kromatike, funkcionalne odnose pa zamenjal z zaporedjem alteriranih akordov ter kromatičnih in enharmosnkih modulacij. Vsekakor je Procházka s samospevom Hrepenenje iz leta 1906 naredil najbolj odločen korak v smeri glasbeno novega, zato se zdi leto dni kasneje toliko bolj presenetljiv povratek h tradicionalnejšim kompozicijsko-tehničnim okvirom v njegovem zadnjem samospevu Večer ${ }^{47}$.

Prav zadnji obrat v tradicionalnejše kompozicijske vode prikaže ustvarjalca, ki je na prelomu stoletja mrzlico za glasbeno novim prebolel tako, da se je distanciral od sočasnih dosežkov glasbene moderne in se bolj ali manj dosledno opredelil za tradicionalnejše okvire, ki so mu ustvarjalno povsem zadoščali. Lahko se ja namreč naslonil na trdna Dvořákova kompozicijsko-tehnična izhodišča. ${ }^{48}$ Tako ni čutil potrebe po ponovnem estetskem vrednotenju tradicionalnih okvirov, prav tako pa ga ni zanimala takrat tako aktualna destrukcija prevzetih formalnih in drugih kategorij. V njemu je bila namreč trdno zakoreninjena tradicija, ki je zanj pomenila edino pomembnejše vodilo pri komponiranju. V slednji je videl garancijo zgodovinske kontinuitete in predvsem zadostno možnost izbire v mreži kompozicijsko-tehničnih postopkov. Josip Procházka torej sodi med tiste skladatelje na prehodu iz 19. v 20. stoletje, ki so razširili tonalni jezik, vendar ga niso nikoli zavrgli v korist modernističnih konstrukcij. Znotraj tonal-

43 Samospev Pesem (NA III/1903-04, 6. zv.) je skladatelj napisal 7. oktobra 1903. Glej samospev Pesem v notnem arhivu Novih akordov Glasbene zbirke NUK pod inventarno številko 364/1955.

44 Samospev Japonski motiv (NA IV/1904-05, 1. zv.) je skladatelj napisal 12. maja 1904. Glej samospev Japonski motiv $\mathrm{v}$ notnem arhivu Novih akordov Glasbene zbirke NUK pod inventarno številko 361/1955.

45 Samospev Sneg pada (NA IV/1904-05, 2. zv.) je skladatelj napisal 12. julija 1904. Glej samospev Sneg pada v notnem arhivu Novih akordov Glasbene zbirke NUK pod inventarno številko 368/1955.

46 Glej samospev Hrepenenje (NA V/1905-06, 6. zV.).

47 Glej samospev Večer (NA VI/1906-07, 1. zV.).

48 PROCHÁZKA, JOSEF, Něco o Dru Dvořákovi jako učiteli, Ur. BLAŽEK, VLASTIMIL, Sborník na pamět 125 let hudby v Praze, Vyšehrad, Praga 1936, 434-435. 
nosti je nadvse iznajdljiv, pri čemer je svoja skladateljska sredstva pogosto uporabil za ponazoritev besedila in stopnjevanje izraznosti. Pri tem se najpogosteje poslužuje tistega besednjaka, ki poglablja diatonično in kadenčno harmonijo in znotraj izbranih meja vodi k naprednejši glasbeni govorici.

Vidik Procházkine stilne aktualnosti in primerljivosti s težnjami in dosežki časa v glasbi na Slovenskem osvetlijo presežne oznake, da naj bi prav Procházka dvignil slovensko komorno glasbo na doslej neznano višino. ${ }^{49}$ Vendar je treba priznati, da je bila aktualnost v začetku 20. stoletja na Slovenskem tudi med »najnaprednejšimi« krogi Novih akordov bolj idejna kot ustvarjalna kategorija. Tako lahko lažje razumemo Krekovo izjavo: »Jaz bom delal kakor do sedaj po svojih skromnih močeh za napredek naše muzike, dasi zahteva ta posel na vse strani dosti samozatajevanja. « ${ }^{50}$ Čeprav se zdi, da je prav "zgostitev evolucijskih procesov« v samospevu na Slovenskem pripeljala slovensko glasbo v kontekst sočasnih glasbenih dogajanj po Evropi, je bilo tudi v tej zvrsti na prelomu stoletja še vedno mogoče čutiti "želeni priokus slovenskosti«.51 Tako so morali skladatelji samospevov za svoj obstoj bolj ali manj jasno postavljene estetske kriterije podrejati kolektivni zavesti in v skladu $s$ »kulturno-politično« realnostjo prispevati $\mathrm{k}$ utrjevanju nacionalne samobitnosti. ${ }^{52}$ Za večino slovenske javnosti so bile namreč tudi v začetku 20. stoletja še vedno najprivlačnejše čitalniške oblike prepevanja na veselicah, pevska društva in posamezni ljubiteljski pevci pa najbolj aktiven delež tedanje slovenske reprodukcije.

Procházka vsekakor ni bil indiferenten do znamenj časa. Kakor večina »masarykovcev« na Slovenskem, je bil prepričan v napredek ne samo v življenjski pragmatiki, temveč tudi v umetnosti. ${ }^{53}$ Slednja se z emancipacijo od preteklega nacionalizma potemtakem ne samo spreminja, temveč tudi izboljšuje. Vsekakor se je dobro vživel v slovenske glasbene okoliščine. Že od vsega začetka je sodil med najbolj aktivne sodelavce revije Novi akordi in uresničeval Krekovo misel, da je treba slovensko glasbo dograjevati s poklicnimi glasbeniki. Nenazadnje je v Novih akordih med češko skladateljsko imigracijo na Slovenskem z naskokom objavil največ kompozicij. Kakor

49 RUDOLF, ANDREJKA, "Procháska, Jožef«, Ur. FRANCE KIDRIČ in FRANC KSAVER LUKMAN, Slovenski biografski leksikon, Zadružna gospodarska banka, Ljubljana 1933-1952, 586.

50 Nadalje zapiše: "Samo ako se založniku zagotovi dovoljno število stalnih naročnikov, mu je mogoče pokriti izgubo na eni strani z morebitnim pribitkom na drugi strani. Samo pod istim pogojem pa je tudi založniku mogoče izdajati muzikalije, ki stoje glede umetniške vrednosti nad nivojem onih skladb, na katere se ozira večina našega občinstva." Glasbena zbirka NUK, Pisni arhiv Novih akordov, Koncept dopisa Benjaminu Ipavcu, št. 107, Ljubljana, 10. december 1907.

51 V samospevih Antona Lajovica, Josipa Pavčiča in Janka Ravnika iz prvega desetletja 20. stoletja so se evolucijski poteki zgostili. Gre za tipično produktivno skrajšano sintezo preteklega, odprto v prihodnjost. Takšna obdobja seveda ne trajajo dolgo, rojevajo pa trajne vrednote, kar slovenska produkcija samospeva zgovorno potrjuje. BERGAMO, MARIJA, „Življenja zmožni« zgodnji samospevi Lucijana Marije Škerjanca, Ur. PRIMOŽ KURET in JULIJAN STRAJNAR, Glasba in poezija, Slovenski glasbeni dnevi, Ljubljana 1990, 195.

52 Dinamika razvoja oziroma sproščenosti ali zavrtosti razvojnih procesov je največkrat odvisna od posegov "družbene strukture«. Tako je "evolucijska zavrtost«lahko posledica "preobremenjenosti z zunajestetsko, na primer nacionalno funkcijo«, ob kateri se ne more razviti »lastna razvojna dinamika«. Ibidem, 194. Za obstoj se je zdelo potrebno predvsem ostati razumljiv širšim množicam. Kulturno-politična realnost je tako prisilila marsikaterega zagrizenega opozicionalca h kompromisnemu sprejetju domačijske glasbene kulture. KARBUSICKY, VLADIMIR, Ideologie im Lied - Lied in der Ideologie, Musikverlage Hans Gerig, Köln 1973, 24-25. Glej tudi: ADORNO, THEODOR W., Philosophie der neuen Musik, Suhrkamp, Frankfurt am Main 1978, 14-16.

53 URBANČIČ, BORIS, Slovensko-češki kulturni stiki, Razmah vsestranskih kulturnih stikov, Ur. MUŠIČ, JANEZ, Založba Mladika, Ljubljana 1993, 19-40. 
večina izmed njih pa svojih ustvarjalnih kvalitet ni mogel v celoti uveljaviti, saj se je moral prilagoditi tu obstoječim razmeram, ki so bile razvojno manj ugodne kot na Češkem.

\section{Bibliografija}

Narodna in univerzitetna knjižnica, Glasbena zbirka NUK, Glasbena matica Ljubljana, Kronika, Dopis odbora Glasbene matice, Ljubljana, 14. februar 1900.

Narodna in univerzitetna knjižnica, Glasbena zbirka NUK, Glasbena matica Ljubljana, Kronika, Uradno potrdilo odbora Glasbene matice o službovanju Josipa Procházke, Ljubljana, 13. januar 1928.

Narodna in univerzitetna knjižnica v Ljubljani, Glasbena zbirka NUK, Notni in pisni arhiv Novih akordov 1901-1914.

ADORNO, THEODOR W., Philosophie der neuen Musik, Suhrkamp, Frankfurt am Main 1978.

ANDREJKA, RUDOLF, »Procháska, Jožef«, Ur. FRANCE KIDRIČ in FRANC KSAVER LUKMAN, Slovenski biografski leksikon, Zadružna gospodarska banka, Ljubljana 1933-1952.

BEKKER, PAUL, Neue Musik, Deutschen Verlags-Anstalt, Stuttgart in Berlin 1923.

BERGAMO, MARIJA, „Življenja zmožni« zgodnji samospevi Lucijana Marije Škerjanca, Ur. PRIMOŽ KURET in JULIJAN STRAJNAR, Glasba in poezija, Slovenski glasbeni dnevi, Ljubljana 1990, 193-201.

BRANBERGER, JOHANN, Das Konservatorium für Musik in Prag, Verlag des Vereines zur Beförderung der Tonkunst in Böhmen, Praga 1911.

BUDKOVIČ, CVETKO, Razvoj glasbenega šolstva na Slovenskem I, Znanstveni inštitut Filozofske fakultete, Ljubljana 1992.

BUSONI, FERRUCCIO, Entwurf einer neuen Ästhetik der Tonkunst, Suhrkamp Verlag, Frankfurt am Main 1974.

ČERNUŠÁK, GRACIAN, »Procházka, Josef», Ur. GRACIAN ČERNUŠÁK in VLADIMÍR HELFERT, Československý hudební slovnik osob a institucí, Státní hudební vydavatelství, Praha 1965.

GRDINA, IGOR, »Hugo Wolf in Josip Ipavec - skica primerjalne biografije«, Ur. ČEPIN, BRANKO, Hugo Wolf - sodobniki in nasledniki, Društvo Huga Wolfa Slovenj Gradec, Slovenj Gradec 2001, 101-108.

GRDINA, IGOR, Josip Ipavec zwischen Musik, Literatur und Medizin, Ur. PETER ANDRASCHKE in EDELGARD SPAUDE, Kunst-Gespräche: musikalische Begegnungen zwischen Ost und West, Rombach, Freiburg im Breisgau 1998, 125-152.

GRDINA IGOR, Predgovor, Ur. GRDINA, IGOR, Josip Ipavec in njegov čas, Založba ZRC SAZU, Ljubljana 2000, 7-10.

JOST, PETER, Brahms und das deutsche Lied des 19. Jahrhunderts, Ur. JOST, PETER, Brahms als Liedkomponist, Franz Steiner Verlag, Stuttgart 1992, 9-37.

KARBUSICKY, VLADIMIR, Ideologie im Lied - Lied in der Ideologie, Musikverlage Hans Gerig, Köln 1973.

KREK, GOJMIR, Hugo Wolf in Slovenci, Ur. KREK, GOJMIR, Novi akordi 11 (1910) 3, L. Schwentner, Ljubljana 1910, 18-20. 
KREK, GOJMIR, Listnica uredništva, Ur. KREK, GOJMIR, Novi akordi 12 (1913) 5-6, L. Schwentner, Ljubljana 1913, 60.

KURET, PRIMOŽ, Deutsches Kulturschaffen in Krain vor dem Ersten Weltkrieg, Ur. LOOS, HELMUT, Deutsche Musik im Osten, Gudrun Schröder Verlag, Sankt Augustin $1997,533-541$.

KURET, PRIMOŽ, Umetnik in družba, Državna založba Slovenije, Ljubljana 1988.

MAHNIČ, JOŽA, Kaj v Župančičevi liriki je pritegovalo skladatelje?, Ur. PRIMOŽ KURET in JULIJAN STRAJNAR, Glasba in poezija, Slovenski glasbeni dnevi, Ljubljana 1990, 70-75.

MOLIČNIK, SIMONA, Novi akordi: zbornik za vokalno in instrumentalno glasbo, Slovenska matica in Slovensko muzikološko društvo, Ljubljana 2006.

MOLIČNIK ŠIVIC, SIMONA, Notni in pisni arhiv Novih akordov 1901-1914, Magistrska naloga, Mentor: prof. dr. KATARINA BEDINA, Oddelek za muzikologijo Filozofske fakultete Univerze v Ljubljani, Ljubljana 2002.

PROCHÁZKA, JOSEF, Něco o Dru Dvořákovi jako učiteli, Ur. BLAŽEK, VLASTIMIL, Sborník na pamět 125 let hudby v Praze, Vyšehrad, Praga 1936, 434-435.

PROCHÁZKA, JOSIP, Kaj bi te vprašal?, Ur. MIHEVC, MARKO, Zgodnji slovenski samospevi, št. 1777, Edicije Društva slovenskih skladateljev, Ljubljana 2005, 118-119.

SANDI SITAR in JANEZ STRNAD, "Stefan, Jožef", Ur. VOGLAR, DUŠAN, Enciklopedija Slovenije, 12. zvezek, Ljubljana 1998.

SMACZNY, JAN, Dvořák's Cypresses: A Song Cycle and its Metamorphoses, Ur. KLAUS DÖGE in PETER JOST, Dvořák-Studien, B. Schott's Söhne, Mainz 1994, 47-64.

ŠKERJANC, LUCIJAN MARIJA, Anton Lajovic, Slovenska akademija znanosti in umetnosti, Ljubljana 1958.

ŠPENDAL, MANICA, Razvoj in značilnosti slovenskega romantičnega samospeva, Obzorja, Maribor 1981.

SUMMARY

Josip Procházka is, after Karl Hoffmeister, one of the most important musical teachers of the Czech musical immigration from the end of the 19th century and the beginning of the 20th century in Slovenia. His compositional work does not seem to be so well-known as his pedagogical work. As Dvořák's student of composition at the Prague State Conservatorium, he began to teach at the school of 'Glasbena matica' in Ljubljana on the recommendation of its directorate in 1898. At the aforementioned institute, he taught piano and composition for more than a decade, and was finally appointed teacher at the secondary school of the State Conservatorium in Prague. With a series of piano compositions and songs, published between 1899 and 1908 in the magazines 'Glasbena zora' and 'Novi akordi', he raised the Slovenian chamber music to a level not known before.
Through a comparative analysis, the author of this paper tries to determine the essential compositional-technical, as well as esthetical directions in eleven Josip Procházka's songs written during the time of his musical-pedagogical work in Slovenia and, by taking into account the findings, to evaluate critically the assertion that the Slovenian chamber music had not reached a high level until that time. Wishing to determine the role and significance of the aforementioned songs in a broader creative context of the song in Slovenia, the author takes a critical view of understanding the progress as the strengthening of 'national originality', which seems to have set significant boundaries to the editorial policy in the seemingly 'non-party' magazine 'Novi akordi'. Thus, it seems that the consequences of national divisions marked the events in the musical culture in Slovenia more or less fatally throughout the 20th century. 